\title{
Prevalence and associated factors of HIV-TB co-infection among HIV patients: a retrospective Study
}

\author{
Melkamu A Zeru
}

Department of Statistics, Bahir Dar University, Ethiopia.

\begin{abstract} co-infection was varies among countries. logistic regressions were applied. associated with TB/HIV co-infection. cell count and WHO clinical stage III.

Keywords: Prevalence; TB; HIV; co-infection; Harari Region.

DOI: https:// dx.doi.org/10.4314/ahs.v21i3.7 2021;21(3): 1003-1009. bttps:// dx.doi.org/10.4314/abs.v21i3.7

\section{Introduction}

TB and HIV co-infection is a major public health problem in many parts of the world. But the prevalence of TB/HIV co-infection was varies among countries. Exploring the reasons of the diversity of TB/HIV co-infection is important for public policy, planning and development of collaborative TB/HIV activities. ${ }^{25}$

Tuberculosis is the most common presenting opportunistic infection and a major public health problem. It is the cause of death among infectious diseases for people living with HIV/AIDS worldwide ${ }^{1-3}$.
\end{abstract}

Background: TB/HIV co-infection is a major public health problem in many parts of the world. But the prevalence of

This study was designed to assess prevalence of TB/HIV co-infection and to determine its factors.

Methods: A retrospective study was done among HIV-positive patients at Hiwot Fana hospital from December, 2014 to 2018. The study participants were selected by simple random sampling. Patients with incomplete chart reviews were excluded and demographic, clinical and laboratory information were analyzed using SPSS and STATA. Uni-vitiate and bivariate

Results: Five hundred fourteen patients were enrolled in this study. Of these, 187(37.4\%) had TB. Bivariate logistic analysis showed that HIV patients with regards to marital status[AOR $=2.6 ; 95 \% \mathrm{CI}=1.19-2.89$ ] , education status $[\mathrm{AOR}=3.74$; $95 \% \mathrm{CI}=2.47-5.66]$, weight less than $50 \mathrm{~kg}[\mathrm{AOR}=2.54 ; 95 \% \mathrm{CI}=1.35-4.81], \mathrm{CD} 4$ level $<200 \mathrm{cells} / \mathrm{mm}^{3}[\mathrm{AOR}=4.57$; $95 \% \mathrm{CI}=2.38-6.86]$ and patient who were at $\mathrm{WHO}$ clinical stage III $[\mathrm{AOR}=7.8 ; 95 \% \mathrm{CI}=5.15-8.55]$ were significantly

Conclusion: The prevalence of TB among HIV patients was high and predicted by marital, education status, weight, CD4

Cite as: Zeru MA. Prevalence and associated factors of HIV - TB co-infection among HIV patients: a retrospective Study. Afri Health Sci.

Worldwide, there were an estimated of 9 million incident cases of tuberculosis in 2013 with $13 \%$ co-infected with HIV. An estimated 1.5 million deaths were

\section{Corresponding author: \\ Melkamu A Zeru, \\ Department of Statistics, Bahir Dar \\ University, Ethiopia. \\ Email: melkamu.ayana@gmail.com}

attributed to TB, excluding deaths among HIV-infected patients. Among infectious diseases, both tuberculosis (TB) and HIV/AIDS represent global public health emergencies. Their mutually detrimental effect on the individual patient and at the population level is most evident in sub-Saharan African countries ${ }^{4}$.

According to the World Health Organization report Ethiopia ranked as the 7 th country among the 22 high burden countries with TB - HIV infection in the world ${ }^{5}$. TB and HIV/AIDS display a lethal bidirectional interaction, with major epidemic overlap. People living with HIV are almost 30 times more likely than HIV-uninfected people to develop TB, and the chronic immune stimulation resulting from active TB accelerates HIV/ AIDS disease progression ${ }^{6-8}$.

Unlike other opportunistic infections, TB disproportionately affects people living with HIV even before any significant drop in CD4+ T cell counts. The key predictor of immune reconstitution inflammatory syndrome (IRIS) is the degree of HIV-induced immunosuppression (low CD4+ count) at ART initiation ?

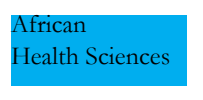

(C) 2021 Zeru MA. Licensee African Health Sciences. This is an Open Access article distributed under the terms of the Creative commons Attribution License (https://creativecommons.org/licenses/BY/4.0), which permits unrestricted use, distribution, and reproduction in any medium, provided the original work is properly cited. 
The current increasing of HIV/AIDS associated tuberculosis shifted the clinical pattern of TB towards smear negative pulmonary TB (PTB) and extra-pulmonary TB (EPTB), which in turn, causes difficulties in the diagnosis and treatment of TB due to unusual clinical picture with increased smear negative acid fast bacilli (AFB) PTB, atypical finding on chest radiography and increased prevalence of EPTB ${ }^{10,11}$

Several studies confirmed that the clinical manifestations of TB in people with HIV are quite different and generally show different patterns as a function of the CD4+ T cell count. In addition, TB can appear at any stage of HIV/AIDS infection, and its presentation varies with the WHO stage and CD4+ lymphocyte count, although it is more frequent when CD4+ T cell count is below 200 cells $/ \mathrm{mm}^{3}{ }^{12}$. Research findings indicated that some HIV-infectd people develop TB, while others do not. This idea implies that being HIV positive is not the only factor for being infected with $\mathrm{TB}$, and there are various determinant factors that contribute to TB/ HIV co-infection ${ }^{12-14}$. Understanding the predictors of TB/ HIV co-infections in the local context is critical point for Ethiopia to improve TB/HIV co-infected patients. In the study area, there were no relevant research done on the prevalence and determinants of TB-HIV co-infection.

The objective of this study was to determine the prevalence and factors associated with TB co- infection among HIV patients in Hiwot Fana hospital in Harar region, which will help to reduce the risk of death and its burden by taking early drug management in the local context.

\section{Methods}

\section{Case Definitions}

The TB case definitions below are based on the level of certainty of the diagnosis and on whether or not laboratory confirmation is:

Tuberculosis suspect. Any person who presents with symptoms or signs suggestive of TB. The most common symptom of pulmonary TB is a productive cough for more than 2 weeks.

Case of tuberculosis. A definite case of TB in which a health worker (clinician or other medical practitioner) has diagnosed TB and has decided to treat the patient with a full course of TB treatment. Any person given treatment for TB should be recorded as a case. Incomplete trial TB treatment should not be given as a method for diagnosis.
Definite case of tuberculosis. A patient with Mycobacterium tuberculosis complex identified from a clinical specimen, either by culture or by a newer method such as molecular line probe assay.

\section{Study Design and Area}

This study was a hospital based retrospective study addressing the prevalence of TB among HIV/AIDS. It used data from the HIV patients attending the ART clinic from December, 2014 to December, 2018 in Hiwot Fana hospital in Harari region, Ethiopia. Hiwot Fana Specialized University hospital serves as a referral hospital for the entire Eastern part of Ethiopia, including Eastern Oromia, Dire Dawa city administration, the Somali regional state and the Harari regional state. The facility is treats more than 2,097 HIV positive patients. It is a teaching hospital for Haramaya University health and medical sciences students. Hiwot Fana specialized University hospital obstetric department admits more than 3000 patients per year, with 2664 deliveries.

\section{Sample size and sampling procedure}

The sample size was determined by taking the estimated proportion (P) of TB15 among people with HIV positive ratio $=0.1$, margin of error $=2 \%$ and confidence level $=95 \%$, and the required sample size became 864 . The 4 years HIV/AIDS patients' case files were identified and the study participants were selected by simple random sampling which gives an equal chance for each subjects to be included in the study, since the nature of target population is heterogeneous, to increase the precision on the study findings. After excluding patients with incomplete medical records, and by adding $10 \%$ to replace the excluded samples, 514 HIV patients who were under ART were considered as study samples to collect the data.

\section{Data collection instruments and procedures}

Data were collected from patients' chart files using a checklist which was prepared by adopting previous studies ${ }^{16-18}$. Pre-test was conducted for the check list before the actual data collection and some variables such as religion, employment status, functional status and alcohol intake were omitted because of incomplete medical records. Otherwise, the checklist was inclusive of the different socio-demographic variables (sex, age, education status, marital status, residence) and clinical characteristics (CD4 count, weight) which were assumed as possible determinants of TB occurrence among people 
with HIV. Data quality was assured by pre-tested data collection and by trained data collectors. Completeness and consistency of data was checked by professionals and data clerks before and after data entry.

Table 1: Variables used in the Study

\begin{tabular}{lll}
\hline S/N & Variable & Description \\
\hline 1. & Sex & $0=$ Female, $1=$ Male \\
2. & Age & $0=<30$ year $1=1 \geq 30$ year \\
3. & Marital status & $0=$ Married, $1=$ Others \\
4. & Education status & $0=$ Illiterate , $1=$ Literate \\
5. & Residence & $0=$ Rural, $1=$ Urban \\
6. & Weight & $0=\leq 50 \mathrm{~kg}, 1=>50 \mathrm{~kg}$ \\
7. & CD4 Count & $0=<200$ cells $/ \mathrm{mm}^{3}, 1=\geq 200$ cells $/ \mathrm{mm}^{3}$ \\
8. & Clinical stage & $0=$ Stage I, $1=$ Stage II $2,=$ Stage III, 3 $=$ Stage IV \\
\hline
\end{tabular}

\section{Data Analysis}

The data was collected and entered in-to the statistical package for social science (SPSS) version 23 and STATA version 14 were used. Frequency and percentage were determined for descriptive analysis of socio-demographic, clinical and laboratory profile of the study subjects. Multivariable logistic regression was used by entering all variables with $\mathrm{p}$ - value $<0.25$ in the bivariate analysis. Finally, logistic regression with forward likelihood variable selection method with $\mathrm{p}$ - value $<0.05$ was used to identify the determinant factors associated with TB/HIV co-infection. The Hosmer-Lemeshow test of goodness of fit was used to model diagnosis with $\mathrm{p}$ - value $>0.05$ provided good fit for the model.

\section{Results \\ Socio-demographic characteristics}

Medical records chart of 514 people living with HIV were used. The mean age of the study participants was 34.17 years with standard deviation (SD) of 3.6 years (34.71 \pm 3.6$)$. Most of the participants were females $270(52.5 \%)$, aged greater than or equal 30 years were $296(57.6 \%)$, living in urban residents were $273(53.2 \%)$. Moreover, 282(54.9\%) of the study participants were married and $310(60.3 \%)$ of the participant were educated (Table 2).

Table 2: Socio-demographic characteristics of study participants in Hiwot Fana Referral Hospital $(\mathrm{n}=514)$

\begin{tabular}{lll}
\hline Variables & Frequency & Percent (\%) \\
\hline Sex & 244 & 47.5 \\
Male & 270 & 52.5 \\
Female & & \\
Age & 21 & 42.4 \\
$<30$ years & 296 & 57.6 \\
$\geq 30$ year & & \\
Marital status & 282 & 54.9 \\
Married & 232 & 45.11 \\
Others & & \\
Education status & 204 & 39.7 \\
Illiterate & 310 & 60.3 \\
Literate & & \\
Residence & & 46.9 \\
Rural & 241 & 53.2 \\
Urban & 273 & \\
\hline
\end{tabular}


There were 514 participants in the study. Of these $187(37.4 \%)$ of them were had HIV/TB co- infection. Of the total, 187 TB/HIV co-infected, female respondents had higher proportion 108(57.8\%) as compared to male respondents $79(42.2 \%)$. Patients whose CD4 count was less than 200 cells $/ \mathrm{mm}^{3}$ had larger proportion $120(64.4 \%)$ as compared to those CD4 count $\geq 200$ cells $/ \mathrm{mm}^{3}$ 67(35.6\%). Furthermore, majority of TB/ HIV co-infected patients 107 (57.2\%) live in urban res- idence. From the same result among TB/HIV patients 95(50.8\%) were married while 92(49.2\%) were others (single, divorced and widowed). Moreover, out of TB/ HIV co- infected patients, 76(40.6\%), were found in WHO clinical stage of III, $73(39 \%)$ in WHO clinical stage of IV, 21(11.2\%) under WHO clinical stage of III and $17(9.1 \%)$ in WHO clinical stage of I . In addition, more than half of co-infected patients $98(52.4 \%)$ but the remaining were illiterates (Table 3 ).

Table 3: Bivariate and Multivariable association of TB/HIV co-infection and independent factors

\begin{tabular}{|c|c|c|c|c|c|c|}
\hline \multicolumn{7}{|c|}{ HIV/TB Co-infected } \\
\hline & Yes & No & COR $(95 \% \mathrm{CI})$ & P-value & AOR $(95 \% \mathrm{CI})$ & P-value \\
\hline \multicolumn{7}{|l|}{ Sex } \\
\hline Male & 79 & 165 & $0.72(0.49-1.03)$ & 0.34 & $0.78(1.31-2.96)$ & 0.230 \\
\hline Female & 108 & 162 & 1 & & 1 & \\
\hline \multicolumn{7}{|l|}{ Age } \\
\hline$<30$ year & 93 & 125 & $0.62(0.43-0.89)$ & 0.15 & $0.52(3.34-5.79)$ & 0.200 \\
\hline$\geq 30$ year & 94 & 202 & 1 & & 1 & \\
\hline \multicolumn{7}{|l|}{ Marital status } \\
\hline Married & 95 & 137 & 1 & & 1 & \\
\hline Others & 92 & 190 & $1.69(1.48-2.01)$ & $0.042 *$ & 2.6(1.19-2.89) & 0.011 \\
\hline \multicolumn{7}{|l|}{ Education status } \\
\hline Illiterate & 98 & 106 & $3.06(2.10-4.44)$ & $0.01 *$ & & \\
\hline Literate & 81 & 229 & 1 & & & \\
\hline \multicolumn{7}{|l|}{ Residence } \\
\hline Rural & 80 & 183 & $1.69(1.18-2.44)$ & 0.2 & $1.97(1.31-2.96)$ & 0.110 \\
\hline Urban & 107 & 144 & 1 & & 1 & \\
\hline \multicolumn{7}{|l|}{ Weight } \\
\hline$\leq 50 \mathrm{~kg}$ & 94 & 129 & $0.64(0.44-0.92)$ & $0.01 *$ & $2.54(1.35-4.81)$ & 0.003 \\
\hline$>50 \mathrm{~kg}$ & 93 & 98 & 1 & & 1 & \\
\hline \multicolumn{7}{|l|}{ CD4 Count } \\
\hline$<200$ cells $/ \mathrm{m}^{3}$ & 120 & 165 & $1.55(2.38-4.79)$ & $0.002 *$ & $4.57(2.38-6.86)$ & $\begin{array}{c}0.007 \\
*\end{array}$ \\
\hline$\geq 200$ cells $/ \mathrm{mm}^{3}$ & 67 & 162 & 1 & & 1 & \\
\hline \multicolumn{7}{|l|}{ Clinical stage } \\
\hline Stage I & 17 & 33 & 1 & & 1 & \\
\hline Stage II & 21 & 87 & $1.49(0.97-2.28)$ & 0.12 & $1.27(0.79-2.03)$ & 0.310 \\
\hline Stage III & 76 & 85 & $0.403(0.23-0.70)$ & $0.04 *$ & $7.8(5.15-8.55)$ & 0.000 \\
\hline Stage IV & 73 & 122 & $0.86(0.44-1.65)$ & 0.28 & $0.29(0.38-1.59)$ & $0 . \dot{500}$ \\
\hline
\end{tabular}

* means statistically significant at $5 \%$ level of significance $(\mathrm{p}$ - value $<0.05)$

* Others means(Single, divorced and Windowed)

The Hosmer-Lemeshow test provided good fit for the model $(\mathrm{p}$-value $=0.673)$

Results in the bivariate analysis showed that the variable residence, WHO clinical stage, education status, marital status, CD4 counts and weight were associated with TB/HIV co- infection. Multivariate analysis in multi- ple logistic regression was used to determine factors of TB/HIV co-infection after adjusting other covariates. From this result, HIV patients whose marital status was different from married were 2.6 times more likely to develop TB than that of married $[\mathrm{AOR}=2.6$; $95 \% \mathrm{CI}$ $=1.19-2.89]$. The illiterate patients were 3.74 times 
more likely to develop TB as compared to the educated patients $[\mathrm{AOR}=3.74 ; 95 \% \mathrm{CI}=2.47-5.66]$. Furthermore, patients whose CD4 cell level $<200 \mathrm{cell} / \mathrm{mm}^{3}$ were 4.57 times more likely to develop TB as compared with cell level $\geq 200 \mathrm{cell} / \mathrm{mm} 3$ [AOR $=4.57 ; 95 \% \mathrm{CI}$ $=2.38-6.86]$. This implies low CD4 cell count is potential determinant for TB/HIV co-infection. Similarly, patients in WHO clinical stage III were 7.8 times more likely to develop TB as compared to that of patient in WHO clinical stage I $[\mathrm{AOR}=7.8 ; 95 \% \mathrm{CI}=5.15-8.55]$ (Table 3).

\section{Discussion}

Tuberculosis is an opportunistic infection in patients with HIV. The prevalence of TB/HIV co- infection in this study was $37.4 \%$. This in line studies in southern Ethiopia $(36.9 \%)^{19}$, in Addis Ababa $(33 \%)^{20}$ and the study conducted in Keniya $(35.6 \%)^{21}$. However, the finding of this study was higher compared to the study result in Amhara region, Ethiopia $(27.7 \%)^{12}$ and a study reported from Nigeria $(11 \%)^{22}$. The possible reasons for this large variation in TB/HIV co- infection across the world may be due to difference in study settings, sample size, diagnosis facility, HIV infection rate, study area and study time.

Being at WHO clinical stage III, having a CD4 level $<200$ cells $/ \mathrm{mm}^{3}$, were identified as risk factors for TB development among HIV patients. These finding is consistent with other Hospital- based studies in Ethiopia ${ }^{12,19}$ and the study in Nigeria ${ }^{23}$. In my study patients with marital status (single, divorced and widowed) were morelikely to develop TB, which is in line with the study of $12 \mathrm{Mitku}$ and others. The literate were less likely to develop TB. This finding is consistent with the results in Ethiopia ${ }^{22}$ and Zambia ${ }^{24}$. In contrast, a study in western Ethiopia ${ }^{12}$ and in Addis Ababa, confirms that high level of education was associated with TB. The contradiction may be possibly due to large proportion TB/ HIV co-infection among illiterate patients in my study area.

\section{Conclusion}

In this study the prevalence of TB/HIV co-infection was high (37.4\%). The risk of TB/HIV occurrence was found to be high among patients whose marital status being single, divorced \& widowed, who was illiterate, whose weight was $<50 \mathrm{~kg}$, CD4 level were below $200 \mathrm{celsl} / \mathrm{mm}^{3}$, and patients in WHO clinical stage III. The large ratio of TB cases among HIV patients requires a special attention for clinical and radiological investigation. Furthermore, since clinical variables were associated with TB/HIV co- infection, health professionals should care for patients who are in WHO clinical stage III, and patient who had lower CD4 counts.

\section{Limitation of the study}

Even though I endeavored to identify factors associated with TB/HIV co infection, the study was conducted in a single hospital with small number of patients, not include variables like viral load, TB before ART, sputum positivity and others, it is difficult to make generalizations about the population and community-based studies are needed to substantiate the study conclusions.

\section{Abbreviations \\ AFT: Acid Fast Bacilli; AOR: Adjusted Odds Ratio; CI: Confidence Interval; COR: Crude Odds Ratio; EPTB: Extra Pulmonary Tuberculosis; HIV: Human Immuno- deficiency Virus; PTB: pulmonary Tuberculosis; TB: Tuberculosis; WHO: World Health Organization}

\section{Acknowledgment}

The authors would like to acknowledge all staff members at Hiwot Fana Hospital, especially ART clinical staffs for their support and cooperation during the study.

\section{Funding}

No funding available for this study.

\section{Availability of data and material}

All data generated or analyzed during this study are available from the corresponding author on reasonable request.

\section{Authors' contribution}

Conceived, designed the study, analyzed the data, supervise the data collectors, wrote the manuscript and approved the final manuscript.

\section{Ethics approval and consent to participate}

Head Department of Statistics, wrote a letter to Hiwot Fana hospital and Chief Clinical Directorate Director of the hospital, read the content of proposal and approved the use of an anonymized dataset of routinely collected data for this study. As the data used in this analysis were collected from chart review, patients were not requested to provide informed consent for the use of their data. Confidentiality was ensured through the removal of patient identifiers prior to the analysis. 


\section{Conflict of interest}

None declared.

\section{Reference}

1. World Health Organization: Tuberculosis. 4th edition, the essentials, edited by Dr. Mario C. Raviglione, World Health Organization, Geneva Switzerland, 2010. 2. Federal Ministry of Health (Ethiopia). Guidelines for clinical and programmatic management of TB, TB/ HIV/AIDS and leprosy in Ethiopia. $5^{\text {th }}$ edition .Addis Ababa: Federal Ministry of Health, 2013.

3. World Health Organization. Consolidated guidelines on the use of antiretroviral drugs for treating and preventing HIV/AIDS infection: recommendations for a public health approach. Geneva: World Health Organization; 2013.

4. World Health Organization: Global Tuberculosis report 2014, Geneva, Switzerland, 2014: World Health Organization

5. World Health Organization: WHO Country Cooperation Strategy 2012-2015, Ethiopia, WHO Regional Office for Africa, Republic of Congo, 2013.

6. World Health Organization. HIV associated TB facts 2013. Geneva: WHO; 2013.

7. Collins KR, Quiñones-Mateu ME, Toossi Z, Arts EJ. Impact of tuberculosis on HIV-1 replication, diversity, and disease progression. Aids Rev 2002; 4: 165-76.

8. Del Amo J, Malin AS, Pozniak A, De Cock KM. Does tuberculosis accelerate the progression of HIV disease? Evidence from basic science and epidemiology. Aids. 1999 Jul 9;13(10):1151-8.

9. Breton G, Duval X, Estellat C, Poaletti X, Bonnet D, Mvondo DM, Longuet P, Leport C, Vildé JL. Determinants of immune reconstitution inflammatory syndrome in HIV type 1-infected patients with tuberculosis after initiation of antiretroviral therapy. Clinical Infectious Diseases. 2004;39(11):1709-12. DOI:10.1086/425742

10. Ejeta E, Box395 PO, Nekemte E. HIV co-infection among tuberculosis patients on Directly Observed Treatment Short Course in Western Ethiopia. Nat Sci. 2014;12(9):68-72.

11. Giri PA, Deshpande JD, Phalke DB. Prevalence of pulmonary tuberculosis among HIV positive patients attending antiretroviral therapy clinic. $N$ AmJ Med Sci. 2013;5(6):367-70. DOI: 10.4103/1947-2714.114169

12. Mitku AA, Dessie ZG, Muluneh EK, Workie DL. Prevalence and associated factors of TB/HIV co-infection among HIV Infected patients in Amhara region, Ethiopia. Afri Health Sci 2016;16(2): 588-595. DOI: 10.4314/ahs.v16i2.29
13. Akanbi MO, Achenbach CJ, Feinglass J, Taiwo B, Onu A, Pho MT, Agbaji O, Kanki P, Murphy RL. Tuberculosis after one year of combination antiretroviral therapy in Nigeria: a retrospective cohort study. AIDS Research and Human Retroviruses. 2013;29(6):931-937. DOI: $10.1089 /$ aid.2012.0231

14. Molaeipoor L, Poorolajal J, Mohraz M, Esmailnasab N. Predictors of tuberculosis and human immunodeficiency virus co-infection: a case-control study. Epidemiology and Health, 2014;36. DOI: 10.4178/epih/ e2014024

15. Federal Ministry of Health (Ethiopia). Guidelines for clinical and programmatic management of TB, TB/ HIV/AIDS and leprosy in Ethiopia. 5th ed. Addis Ababa: Federal Ministry of Health; 2013.

16. Ngowi BJ, Mfinanga SG, Bruun JN, Morkve O. Pulmonary tuberculosis among people living with HIV/ AIDS attending care and treatment in rural northern Tanzania. BMC Public Health. 2008;8:341.

17. Wondimeneh Y, Muluye D, Belyhun Y. Prevalence of pulmonary tuberculosis and immunological profile of HIV co-infected patients in Northwest Ethiopia. BMC Res Notes. 2012; 5:331.

18. Fekadu S, Teshome W, Alemu G. Prevalence and determinants of Tuberculosis among HIV infected patients in south Ethiopia. The Journal of Infection in Developing Countries. 2015;9(08):898-904. DOI: 10.3855/ jidc.5667

19. Negussie A, Debalke D, Belachew T, Tadesse F. Tuberculosis co-infection and its associated factors among People living with HIV/AIDS attending antiretroviral therapy clinic in southern Ethiopia: a facility based retrospective study. BMC Research Notes. 2018 ;11(1):417.

20. Kibret KT, Yalew AW, Belaineh BG, Asres MM. Determinant factors associated with occurrence of tuberculosis among adult people living with HIV after antiretroviral treatment initiation in Addis Ababa, Ethiopia: a case control study. PLoS One. 2013. DI:10.1371/ journal.pone.0064488

21. Mbithi A, Gichangi A, Kim AA, Katana A, Weyenga $\mathrm{H}$, Williamson J, Robinson $\mathrm{K}$, Oluoch $\mathrm{T}$, Maina WK, Kellogg TA, De Cock KM. Tuberculosis and HIV at the national level in Kenya: results from the second Kenya AIDS Indicator Survey. Journal of Acquired Immune Deficiency Syndromes (1999). 2014 ;66(Suppl 1):S106. DOI: 10.1097/QAI.0000000000000120

22. Taha M, Deribew A, Tessema F, Assegid S, Duchateau L, Colebunders R. Risk factors of active tuberculosis in people living with HIV/AIDS in southwest Ethiopia: a case control study. Ethiopian Journal of 
Health Sciences. 2011;21(2):131-40.DOI: 10.4314/ejhs. v21i2.69053

23. Gunda DW, Maganga SC, Nkandala I, Kilonzo SB, Mpondo BC, Shao ER, Kalluvya SE. Prevalence and Risk Factors of Active TB among Adult HIV Patients Receiving ART in Northwestern Tanzania: A Retrospective Cohort Study. Canadian Journal of Infectious Diseases and Medical Microbiology. 2018. DOI: 10.1155/2018/1346104
24. Kapata N, Chanda-Kapata P, Michelo C. The social determinants of tuberculosis and their association with TB/HIV co-infection in Lusaka, Zambia. Medical Journal of Zambia. 2013;40(2):48-54.

25. Gao J, P Zheng P, Hua Fu. Prevalence of TB/ HIV Co-Infection in Countries except China: A Systematic Review and Meta-Analysis. PLoS One, 2013 journals.plos.org. DOI: 10.1371/journal.pone.0064915 